\title{
Characteristics of Korean Secondary Female PE Teachers' Voluntary Professional Development
}

\author{
Okseon Lee ${ }^{\mathrm{a}, \mathrm{b}^{*}}$, Yeri Hong ${ }^{\mathrm{c}}$, \& Ara Cho \\ ${ }^{a}$ Professor, Department of Physical Education, Seoul National University, Seoul, Korea \\ ${ }^{b}$ Researcher, Institute of Sport Science, Seoul National University, Seoul, Korea \\ ${ }^{c}$ Doctoral Student, Department of Physical Education, Seoul Nationa University Seoul, Korea
}

\begin{abstract}
The purpose of this study was to investigate the characteristics of Korean female secondary PE teachers' voluntary professional development(PD) activity participation in relation to female PE teachers' perceived professional identity. Data were collected from online questionnaires $(n=107)$ and in-depth interviews $(n=15)$ with female secondary PE teachers. Findings revealed that female PE teachers' voluntary professional development activities were characterized as: (a) prevalence in sport skill development activities in order to overcome relatively a low level of sport skills than that of male PE teachers, (b) dominance of self-directed learning activities with the Internet search or reading, and (c) seeking ideal mix of theory and practice by participating in teacher learning communities. Female PE teachers' voluntary PD participation was related to their notion of PE subject as sport skills-centered subject, relatively weak professional identity due to lack of sport skills compared with male teachers, and perceiving teacher learning community as a viable learning context to support their everyday pedagogical PE practice.
\end{abstract}

Key words: secondary school, female PE teachers, continuing professional development, professional identity

\section{Introduction}

Professionals are lifelong learners who should be equipped with professional knowledge, skills, and dispositions to obtain qualification and thereafter should make efforts to continuously update and develop the latest knowledge and skills in the field. Therefore, professionals should participate in continuing

Submitted : 13 September 2021

Revised : 13 December 2021

Accepted : 21 December 2021

Correspondence : okseonlee@snu.ac.kr professional development (CPD) as a part of lifelong learning and development (Bae, Jung, \& Lee., 2013).

As physical education (PE) is expected to provide educational solutions to social problems such as adolescent obesity, school violence, and depression, the demand for cultivation of the professionalism of PE teachers is increasing (Berg \& Lahelma, 2010; Choi, 2016; Mooney \& Hickey, 2012). Consequently, there has been increasing attention on PE teachers' CPD both theoretically and empirically (Armour et. al., 2017; Lee et. al., 2020; Parker et. al., 2012; Tannehill et al. al., 2021). 
South Korea also encourages physical education(PE) teachers to participate in CPD to foster their professionalism, and PE teachers participate in various CPD activities ranging from mandatory, institution-based CPD to voluntary CPD (Desimone, 2011). However, it was found that, despite the government's full financial support and policy initiatives, official CPD has little effect beyond mandatory participation, and its content does not closely match with the professional identity of PE teachers (Lee et al., 2019). On the other hand, voluntary CPD was found to be effective for teachers' learning and improving classroom instruction because it allows autonomy and agency in learning with teachers (Lee et. al., 2017; Patton et. al., 2013). Consequently, there should be more studies on voluntary CPD is required.

Recently, the ratio of female PE teachers which has been gradually increasing (Kim, 2020; Lee el al., 2021), within PE teaching profession, which has been traditionally regarded as a hyper-masculine occupation. Most studies one female PE teachers, however, reported that female PE teachers were "deficient beings", who were experiencing various difficulties in adapting themselves to the school field (Kang \& Park, 2019; Lee et al., 2021). Female PE teachers experienced difficulties due to gender-stereotyped expectations of schools (Yoon, 2020), role conflicts (Lyu, 2011), and difficulties in cultural adaption (Kwon, 2013). Although many studies focused on female PE teachers' difficulties and deficiencies, few studies have explored what kind of effort they make for professional development. Therefore, the purpose of this study was to examine characteristics of female PE teachers' voluntary professional development activities. The specific research question was: 'What are the characteristics of female secondary PE teachers' voluntary professional development? The proposed study is expected to provide information on designing CPD programs for female secondary PE teachers' professional growth and professional identity development.

\section{Methods}

The data were collected through online open-ended questionnaires and semi-structured in-depth interviews with the participants. The online questionnaires were administered with 107 female PE teachers working at middle and high schools located in Seoul, Korea. The background information of the participants is as shown in Table 1. For the in-depth interviews, 15 out of the 107 participants who expressed their intention to participate were selected in consideration of their length of teaching experience, educational backgrounds, and school levels. The protocol of this study was approved

Table 1. Background information of online questionnaire survey participants

\begin{tabular}{|c|c|c|}
\hline \multicolumn{2}{|c|}{ Category } & \multirow{2}{*}{$\begin{array}{c}\mathbf{N}(\%) \\
30(28.0 \%)\end{array}$} \\
\hline \multirow{4}{*}{ Age } & $20-29$ & \\
\hline & 30-39 & $47(43.9 \%)$ \\
\hline & $40-49$ & $22(20.6 \%)$ \\
\hline & $50-59$ & $8(7.5 \%)$ \\
\hline \multirow{2}{*}{ School level } & Middle school & $62(57.9 \%)$ \\
\hline & High school & $45(42.1 \%)$ \\
\hline \multirow{3}{*}{ Academic degree } & Bachelor & $66(61.7 \%)$ \\
\hline & Master & $40(37.4 \%)$ \\
\hline & Doctor & $1(0.9 \%)$ \\
\hline \multirow{4}{*}{ Years of teaching experience } & $0-5$ years & $51(47.7 \%)$ \\
\hline & 6-10 years & $25(23.4 \%)$ \\
\hline & 11-15 years & $10(9.3 \%)$ \\
\hline & At least 16 years & $21(19.6 \%)$ \\
\hline
\end{tabular}


by the University's Institutional Review Board, and informed consents were obtained from all participants.

\section{Online Questionnaires}

The online questionnaire was administered in order to explore female secondary PE teachers' voluntary professional development activities. The questionnaire asked questions like: (a) list all the voluntary CPD activities you had participated in for the last three years, (b) select the most effective CPD activity among you listed and write down the reason, (c) select the least effective CPD activity among you listed and provide reasons, (d) reasons for participation in voluntary CPD activities, (e) impact of voluntary CPD activities on teachers' lives and teaching, (f) strengths and weaknesses of voluntary CPD activities, $(\mathrm{g})$ facilitators and barriers to CPD participation. The questionnaires were composed of open-ended questions in order to obtain diverse information from participants.

\section{Interviews}

The in-depth interviews were conducted with 15 teachers (Table 2) selected from among the teachers who participated in the online questionnaire surveys. In the interviews, questions were asked about (a) experiences of participating in voluntary CPD activities, (b) relative strengths and weaknesses of voluntary CPD activities and formal CPD activities, (c) factors influenced facilitating or inhibiting voluntary CPD activities, and (d) perceived effects of voluntary CPD. The interviews were conducted as non-face-to-face Zoom Meetings due to the COVID-19 situation and were recorded using Zoom's voice recording function and transcribed with verbatim.

\section{Data Analysis}

Descriptive frequency analysis was conducted on the types of CPD activities. Responses to open-ended questions were coded for content analysis. Meaningful sentences from open-ended questions and in-depth

Table 2. Demographic Information of Participants

\begin{tabular}{ccccc}
\hline \hline Participant & age & Teaching experience & School level & Academic degree \\
\hline T01 & 28 & 4 years & Middle school & Master's degree \\
T02 & 37 & 13 years & Middle school & Master's degree \\
T03 & 26 & 2 years & Middle school & Master's degree \\
T04 & 36 & 13 years & Middle school & Master's degree \\
T05 & 26 & 2 years & Middle school & Bachelor's degree \\
T06 & 30 & 4 years & High school & Bachelor's degree \\
T07 & 59 & 32 years & Middle school & Master's degree \\
T08 & 57 & 30 years & Middle school & Master's degree \\
T09 & 25 & 1 year & Middle school & Bachelor's degree \\
T10 & 45 & 20 years & School vice-commissioner & Master's degree \\
T11 & 54 & High school & Master's degree \\
T12 & 37 & Mears & Middle school & Bachelor's degree \\
T13 & 38 & 14 years & Middle school & Master's degree \\
T14 & 32 & 7 years & Middle school & Bachelor's degree \\
T15 & 41 & 16 years & High school & Bachelor's degree \\
\hline \hline
\end{tabular}


interview data were entered into Nvivo 12, and content analysis was conducted in three stages (Miles, Huberman \& Saldana, 2014). In the first stage, initial codes were created for the types of voluntary CPD that secondary school female PE teachers participate in from the responses to online questionnaire surveys and open-ended questions. In the second stage, similar types of codes were grouped into focus codes, and in the last stage, the codes were integrated to generate topics that describe the aspect of participation. Trustworthiness of data was ensured through member check and peer debriefing (Creswell, 2009).

\section{Findings}

\section{Types of female PE teachers' voluntary CPD activities}

As a result of the online survey, it was found that secondary school female PE teachers were participating in nine types of voluntary professional development activities as shown in Table 3. Among them, contents related to sports skill development, such as personal physical fitness exercise $(25.0 \%)$ and private lessons related to sports $(22.6 \%)$, were dominant, followed by self-directed learning such as Internet data search $(18.3 \%)$ and reading $(8.8 \%)$. In addition, participation in teacher learning community (13.4\%), which has been in the spotlight recently, also showed a high ratio indicating that it is a major factor in voluntary CPD activities.

\section{Characteristics of Female PE teachers' voluntary CPD activities}

\section{Dominance in sport skills-centeredness}

In voluntary CPD activities of secondary school female PE teachers, top priority was given to cultivating sports skills such as personal physical fitness exercise and private lessons for sport skills development. The sport skills-centeredness of voluntary CPD activities was related to the notion of PE subject perceived by female PE teachers as well as their perceived level of professionalism (Armour \& Yelling, 2010; Lee et al., 2019). That is, secondary school female PE teachers had the idea that PE is a subject based on physicality, and accordingly, the level of sports skills that teachers have is a measure of professionalism. Female PE teachers perceived that they were at lower positions than male peer teachers or male students in the school hierarchy formed according to the level of sports skills. Regarding the foregoing, a teacher (T13) pointed out the hierarchy in PE classes created by sports skills, "Because I am a female PE teacher, male students first look down on me and think that my sport skills are inferior to them, and I cannot play sport well."

Table 3. Types of participation in voluntary professional development activities

\begin{tabular}{ccc}
\hline \hline Type of CPD & Frequency(n) & Percentage(\%) \\
\hline Personal physical fitness exercise & 82 & $25.0 \%$ \\
Private lesson for sport item & 74 & $22.6 \%$ \\
Internet sports data search & 60 & $18.3 \%$ \\
Teacher learning community & 45 & $13.4 \%$ \\
Reading & 29 & $8.8 \%$ \\
Watching sporting events & 23 & $7.0 \%$ \\
Entrance to graduate school & 14 & $4.3 \%$ \\
Participation in conferences and workshops & 1 & $0.3 \%$ \\
Instructional training by item & 1 & $0.3 \%$ \\
\hline \hline
\end{tabular}


In this culture, it was shown that female PE teachers recognized that resolving the "deficiency" in sports skill level as the top priority for voluntary CPD activities and were doing personal physical fitness exercise or receiving private lessons for sport skills development to supplement the deficiency. Female PE teachers were feeling burden for demonstrating sports skills, and since they were feeling. that they were daunted due to their relatively lower levels of sport skills compared to male PE teachers.

There are several reasons why I am daunted, and the issue of demonstration is the most serious. Because I am a teacher, I think I should show something and teach it in class, but it is difficult for me to demonstrate because I have not experienced diverse sports. My level of sport skills is low (...) Learning sports skills is the most urgent thing (Interview, T03).

It shows that female PE teachers' voluntary CPD activities were limited to a passive sense by focusing on reducing their deficiencies rather than pursuing "development" in an active sense. That is, female PE teachers equated the level of sports skills with teachers' professionalism through these voluntary CPD activities (Lee et al., 2019). Consequently, the female PE teachers' sport skills-centeredness in CPD had limitations of reproducing the problems of physicality and competitiveness of existing physical education subjects and being unable to criticize the problems.

\section{Prevalence of individual learning activities}

The voluntary CPD of secondary school female PE teachers was found to have a strong nature of individual learning rather than social learning. Both 'personal' physical fitness exercise for cultivating sports skills and 'private lessons' for sport skills development had the nature of personal learning rather than social learning. In addition, it was found that secondary school female
PE teachers were participating in Internet data search, reading, and watching sports events individually rather than sharing with others. These activities were characterized by personal exploration and learning rather than collective knowledge formed and shared through interaction with others. Although Internet data search or reading can satisfy teachers' immediate needs such as finding appropriate teaching resources, it is limited to one-shot solution which is not shared and constructed in relation to social interaction. Given that the true knowledge should be constructed with social interaction rather than mere acquisition of information (Sfard, 1998), individually skewed learning has limitation in teacher development.

First, the reason why female PE teachers prefer personal physical fitness exercise or private lessons for sport skills development was found to be the fact that they are alienated from activities operated as groups and teams because differences in sports skills levels between them and male PE teachers. The following interview data show that female PE teachers prefer individual activities rather than community activities with social interaction as their sports skill levels are relatively lower than those of male PE teachers.

In fact, it is a bit difficult to participate in training to play badminton, volleyball, if you are not good at these skills. If you are not good at skills, you may be a hindrance to others, feel like you are causing a nuisance to others with your poor skills, and others' eyes are burdensome (...). In addition, in the case of secondary schools, male teachers' participation rates in skill training are high. As a result, the training is conducted mainly for males, so that female teachers' participation is more difficult (Interview, T10).

As shown in the interview data, female PE teachers perceive that males were dominant in the professional development programs for female PE teachers and consequently, they prefer the form of personal learning 
to escape from social learning in fear of exposure of their low levels of physical ability and sport skills.

Second, it was found that individual CPD activities such as Internet information search, reading, and watching sports were used for the purpose of immediately obtaining data and information necessary for PE classes (Kyndt et al., 2016). In particular, the participants emphasized that individual activities have advantages in immediacy and speed, with the statement, "I like individual activities because I can get the materials needed for class immediately without going through the complicated process of coordinating with others" (T14). In addition, activities such as reading and watching sports games were found to be indirect CPD activities to obtain emotional support for relieving stress caused by excessive schoolwork rather than being directly related to classes. As such, the CPD of female PE teachers was found to be affected by the difference in sports ability between men and women, the immediate search of materials necessary for classes, and the relief of occupational stress.

Seeking amalgam of theory and practice with teacher learning community

Female PE teachers pointed out that the biggest problem in the formal CPD activities lies in the theory-practice gap. In order to overcome these shortcomings, it was found that they prefer activities in which theory and practice are properly integrated in voluntary CPD. The following interview data shows the limitations of formal CPD carried out as one-shot activities and the fact that they prefer continuous community-type activities to overcome these limitations.

Formal training programs end when you just heard something and thought that it was good in many cases because the durations are short, and the situations do not enable you to apply what you learned theoretically to reality. Unless a community is formed there, I don't think a short training can provide large effects. I think training in which a network or community is formed is definitely helpful (Interview, T07).

To solve the problem as such, female PE teachers recognized the teacher learning community as an alternative form of CPD. In particular, the teacher-learning community was thought as an alternative approach to integrated application of theories and knowledge related to teaching and learning and generating knowledge.

I'm currently attending a district-based teacher learning community, where although cases are shared, but these days, meetings are held in a form in which theories and practical skills are integrated. The teachers there taught me from $a$ learner's point of view. Then I could change what I learned to be a little easier and apply it to the students as well. Therefore, I felt that learning how to apply practical skills in classes was more meaningful than just being good at skills of sports myself (Interview, T09).

Regarding positive aspects of teacher learning community, participants reported that it allowed continuous social interaction with people who had shared purpose as well as facilitating transfer of knowledge to their PE teaching practice. In addition, female PE teachers mentioned attending graduate school as a CPD activity for integrating theories and practice. One participant (T06) said, "I learned about theories and teaching techniques through classes or conversations with teachers at the graduate school" thereby showing satisfaction with sharing actual teaching methods and cases as well as theories in the community of which all the members tended to be active in knowledge acquisition. While participating in communities, the participants integrated theories and practice, and in particular, they restored a sense of community to overcome isolated feelings in the field. 


\section{Discussion}

The purpose of this study was to identify the characteristics of voluntary professional development activities of female secondary PE teachers.

First, the findings revealed that voluntary CPD activities of secondary school female PE teachers were concentrated on the 'cultivation of sports skills'. This seems to have been affected by female PE teachers' equating the level of professionalism with sports skills and fitness levels (Lee et. al., 2018). In this regard, Noonan (2019) and Lee et al. (2017) suggested that the contents and motives for participating in professional development programs vary according to how teachers perceive their own identity, and that the learning and growth of teachers also vary accordingly. In particular, in the PE subject, where physicality is emphasized, female PE teachers' deficiency-centered perception that the level of physical strength and sports skills of them is lower compared to that of male teachers became an important factor for female PE teachers' participation in sports-oriented CPD. However, in light of the situation where the purposes of PE subjects are expanding from sports-oriented ones to competency development-oriented and character development-oriented ones, voluntary professional development programs for female teachers are biased, and can be said to have limitations in cultivating diverse professionalisms dealt with in the PE curriculum (Cordingley, 2015).

Second, it was found that female PE teachers prefer personal learning such as personal physical fitness exercise or private lessons rather than activities that involve active interaction. It was caused by the fact that female PE teachers were relatively neglected or uninterested in learning because the existing CPD was led by teachers with excellent motor skills or male teachers. It was found that female PE teachers who had negative experience of the reproduction of the negative PE classes (Cazers \& Curtner-Smith, 2017) experienced by them as girl students during their school days preferred individualized learning. Therefore, for female $\mathrm{PE}$ teachers to restore the social nature of learning, the sports-oriented professional development programs should be restructured. In particular, it is necessary to restructure the professional development programs so that female PE teachers can feel the programs as physically and psychologically safe learning spaces even if their motor skills are low (Driver, 1995; Choi et al., 2004).

Third, Internet search, reading, and watching sports games as individual CPD activities were found to play a role in the function of a 'class support ambulance' (Lee et al., 2018, p.11) that satisfies the immediate needs of teachers and relieving the stress of teachers. Given the foregoing, individual CPD activities were playing a role in satisfying the immediate needs of female PE teachers, but critical attention is needed for the development of more in-depth professionalism. Given the reported limitations of one-shot, fragmented, off-context professional development activities, there should be concerted effort to promote collaborative, sustained, and context-embedded professional development program for female PE teachers (Armour, Makopoulou, \& Chambers, 2008; O'Sullivan \& Deglau, 2006).

Fourth, as female PE teachers recognized the importance of learning close to the field, they were looking for community-type professional development activities and network formation as alternatives. In order to develop professionalism beyond the theory-practice gap (Lee et. al., 2019), alternative professional development activities such as teacher learning communities are necessary. In particular, teachers who gathered voluntarily create knowledge beyond simple sports skill improvement by sharing a vision and generating and applying knowledge for practice. Above all, the teacher learning community will help form a professional identity by reflecting the needs and demands of female PE teachers by overcoming individually fragmented CPD activities of female PE teachers (Parker et al., 2012). 


\section{Conclusion}

This study focused on analyzing the aspects and characteristics of the voluntary CPD of secondary school female PE teachers. The voluntary CPD of female PE teachers was found to be related to female PE teachers' notion of PE subject and their perceptions of professional identity. Based on these findings, the following implications can be suggested.

First, future studies should examine female PE teachers' participation in professional development activities more specifically according to the stage of teacher development. Influencing factors such as teachers' image, the value of education, and philosophical ideals that change according to teacher development stages such as induction, growth, frustration, and stabilized stage (Burke, Christensen \& Fessler, 1984) should be explored and the aspects of CPD activities in which they participate should be examined according to the influencing factors. Studies as such can contribute to the exploration of the identities of female PE teachers according to their developmental stages and development of effective programs to support the identities.

Second, follow-up studies are necessary to examine how secondary school female PE teachers participation in voluntary CPD affects teachers' learning and students' achievement. The ultimate goal of teacher professional development programs is to enhance student achievements through changes in classrooms beyond teachers' learning. Compared to formal CPD activities, voluntary CPD has the characteristics of being deeply related to teachers' lives and everyday practice as well as being more diverse in types. Therefore, it is necessary to study how the combinations of various voluntary professional development activities affect teachers' learning and growth and students' achievement.

Third, it is necessary to provide psychologically and physically safe learning environment for female PE teachers. The formation of professional networks and the sharing of important knowledge through the networks are the greatest strengths of the voluntary professional development activities. Therefore, policy level of support is necessary so that female PE teachers with common interests can form a voluntary community based on the issues and needs they face, cultivate their professional identity as female PE teachers and develop professionalism.

\section{Acknowledgement}

This work was supported by the Ministry of Education of the Republic of Korea and the National Research Foundation of Korea(NRF-2020S1A5A2A01 046075).

\section{References}

Armour, K., Makopoulou, K., \& Chambers, F. (2012). Progression in physical education teachers' career-long professional learning: Conceptual and practical concerns. European Physical Education Review, 18(1), 62-77.

Armour, K., Quennerstedt, M., Chambers, F., \& Makopoulou, K. (2017). What is 'effective' CPD for contemporary physical education teachers? A Deweyan framework. Sport, Education and Society, 22(7), 799-811.

Armour, K. M., \& Yelling, M. R. (2004). Continuing professional development for experienced physical education teachers: Towards effective provision. Sport, education and society, 9(1), 95-114.

Bae, E., Jung, B., \& Lee, M. (2013). The Mediating Effects of Participation Motivation on the Relationship between Organizational Learning Transfer Climate and Learning Transfer in Professional Engineers' Continuing Professional Development Activities. Journal of Engineering Education Research, 16(2), 11-23.

Berg, P., \& Lahelma, E. (2010). Gendering processes in the field of physical education. Gender and 
education, 22(1), 31-46.

Burke, P. J., Christensen, J., \& Fessler, R. (1984). Stages of teachers careers: Implications for professional development. Recuperado de la base de datos ERIC,.(ED227054)

Cazers, G., \& Curtner-Smith, M. D. (2017). Robin's Story: Life History of an Exemplary American Female Physical Education Teacher. Journal of Teaching in Physical Education, 36(2), 197-208.

Choi, K., Park, J., Choi, B., Nam, J., Choi, K., Lee, K. (2004). Analysis of verbal interaction between teachers and students in middle school science classroom. Journal of The Korean Association for Science Education, 24(6), 1039-1048.

Choi, W. (2016). A Qualitative Study on Gender Perception of Female Pre-service PE Teachers. Korean Society For The Study Of Physical Education, 21(1), 1-13.

Cochran-Smith, M., \& Lytle, S. L. (1999). Relationships of knowledge and practice: Teacher learning in communities. In A. Iran-NeJad \& C. D. Pearson (Eds.), Review of Research in Education (Vol, 24, pp. 249-306). Washington, DC: American Educational Research Association.

Cordingley, P. (2015). The contribution of research to teachers' professional learning and development. Oxford Review of Education, 41(2), 234-252.

Creswell, J. W. (2009). Research design: Qualitative, quantitative, and mixed methods approaches, 3th Ed. London: Sage.

Desimone, L. M. (2011). A primer on effective professional development. Phi Delta Kappan, 92(6), 68-71.

Driver, R. (1995). Constructivist approaches to science teaching. In L. P. Steffe \& J. Gale (Eds.), Constructivism in education (pp. 385-400). Hillsdale, N. J.: Lawrence Erlbaum Associates, Inc. Kang, J., \& Park, S. (2019). The First Experience of a Female Elementary School PE Specialist Teacher Improving Professionalism in PE Class. Journal of Korean Association of Physical Education and
Sport for Girls and Women, 33(4), 15-31.

Kim, H. (2020). Exploration on the Teacher Identity Formation and Factors of Secondary School Female Physical Education Teachers. Unpublished Master Dissertation. Seoul National University, Seoul, South of Korea.

Kwon, M. (2013). A Self Study on Difficulties Experienced as a Soccer Team Director of Female Middle School Physical Education Teacher. Journal of Korean Association of Physical Education and Sport for Girls and Women, 27(2), 1-18.

Kyndt, E., Gijbels, D., Grosemans, I., \& Donche, V. (2016). Teachers' everyday professional development: Mapping informal learning activities, antecedents, and learning outcomes. Review of Educational Research, 86(4), 1111-1150.

Lee, O., Cho, A., Hong, Y. (2021). From Female Students to Female PE Teachers: Exploring the Influence of Beginning Female PE Teachers' PE Biographies on Induction Experience. Journal of Research in Curriculum \& Instruction, 25(3), 207-217.

Lee, O., Choi, E., Griffiths, M., Goodyear, V., Armour, K., Son, H., \& Jung, H. (2019). Landscape of secondary physical education teachers' professional development in South Korea. Sport, Education and Society, 24(6), 597-610.

Lee, O., Choi, E., Goodyear, V., Griffiths, M., Son, H., Jung, H., \& Lee, W. (2020). Exploration of the Patterns of Physical Education Teachers' Participation Within Self-Directed Online Professional Development. Journal of Teaching in Physical Education(published online ahead of print 2020).

Lee, O., Choi, E., Jung, H., \& Yoon, K. (2017). A systematic review of physical education teachers' continuing professional development. Korean Journal of Sport Pedagogy, 24(3), 1-23.

Lee, O., Son, H., Choi, E., \& Lee, W. (2018). Characteristics of secondary physical education teacher's voluntary professional development 
activities - Focusing on activities other than formal teacher training courses. Korean Journal of Sport Pedagogy, 25(1), 1-23.

Lyu, M. (2011). We Preferred Female Teacher in Physical Education(PE) Classes?: Focused on Exercise Interest, Class Effort, and Teacher Feedback Perceived in PE Classes. Korean Journal of Sport Science, 22(2), 1999- 2007.

Miles, M. B., Huberman, A. M., \& Saldana, J. (2014). Qualitative data analysis: A methods sourcebook, 3th Ed. London: Sage.

Mooney, A., \& Hickey, C. (2012). Negotiating masculine hegemony: female physical educators in an all-boys' school. Asia-Pacific Journal of Health, Sport \& Physical Education, 3(3), 199-212.

Noonan, J. (2019). An affinity for learning: Teacher identity and powerful professional development. Journal of Teacher Education, 70(5), 1-12.

O'Sullivan, M., \& Deglau, D. (2006). Principles of professional development. Journal of teaching in Physical Education, 25(4), 441-449.
Patton, K., Parker, M., \& Pratt, E. (2013). Meaningful learning in professional development: Teaching without telling. Journal of Teaching in Physical Education, 32, 441-459.

Parker, M., Patton, K., \& Tannehill, D. (2012). Mapping the landscape of communities of practice as professional development in Irish physical education, Irish Educational Studies, 31(3), 311-327.

Sfard, A. (1998). On two metaphors for learning and the dangers of choosing just one. Educational researcher, 27(2), 4-13.

Tannehill D, Demirhan G, Čaplová P, Avsar Z. (2021). Continuing professional development for physical education teachers in Europe. European Physical Education Review, 27(1), 150-167.

Yoon, H-S. (2020). A narrative inquiry on teaching experience of boxing class of a novice female physical education teacher in middle school, Korean Society for the Study of Physical Education, 25(1), 77-92. 